\title{
Co-expressing Turnip Crinkle Virus-coat protein with the serine protease a-thrombin precursor (pFIla) in Nicotiana benthamiana Domin
}

\author{
Melina Laguia-Becher ${ }^{1,2} \cdot$ Zurima Zaldúa $^{3}$ - Weijie $\mathrm{Xu}^{3} \cdot$ Patricia Laura Marconi ${ }^{2,4} \cdot$ William Velander ${ }^{3}$. \\ María Alejandra Alvarez ${ }^{2,4}$ (D)
}

Received: 23 April 2018 / Accepted: 14 December 2018 / Editor: Baochun Li

(C) The Society for In Vitro Biology 2019

\begin{abstract}
The serine protease $\alpha$-thrombin (FIIa) plays a fundamental role in blood clotting. In the present report, a FIIa precursor (pFIIa) was expressed in Nicotiana benthamiana Domin. The expression construct featured the Kozak consensus sequence and the 2S2 Arabidopsis thaliana (L.) Heynh. signal peptide to direct the protein into the secretory pathway (sec-pFIIa). A version carrying the KDEL endoplasmic reticulum (ER) retention signal (pFIIa-ER) was also constructed. Transient expression of pFIIa in $N$. benthamiana leaves was achieved by Agrobacterium tumefaciens infiltration. The influence of post-transcriptional gene silencing (PTGS) was analyzed by co-infiltrating with an A. tumefaciens strain carrying the construct for the Turnip Crinkle Virus-coat protein (TCV-CP) known for interfering with PTGS. Reverse transcription polymerase chain reaction and Western blot analyses confirmed the presence of the corresponding messenger RNA and the recombinant pFIIa protein in plant extracts. A positive effect of the addition of the PTGS inhibitor was demonstrated. The accumulation of sec-pFIIa and pFIIa-ER was estimated to be $6 \mu \mathrm{g} \mathrm{g}^{-1}$ fresh weight (FW) $\left(0.07 \%(w / w)\right.$ total protein concentration; TPC) and $17 \mu \mathrm{g} \mathrm{g}^{-1} \mathrm{FW}(0.21 \%(w / w)$ TPC), respectively. Furthermore, stably transformed callus and suspension cultures were obtained. The recombinant protein was detected only in the biomass of the pFIIa-ER cell suspension line at a concentration of $0.25 \mu \mathrm{g} \mathrm{mL}^{-1}(0.017 \%(w / w)$ of total soluble protein). This appears to be the first report describing the expression of a precursor of FIIa in plants.
\end{abstract}

Keywords Alpha-thrombin · Plant-made recombinant protein · Agrobacterium tumefaciens infiltration · Post-transcriptional gene silencing $\cdot$ Plant cell suspension cultures

\section{Introduction}

Blood clotting is a complex mechanism that results from interactions between blood, vessels, platelets, and coagulation factors. The blood-clotting cascade is triggered by any injury,

María Alejandra Alvarez

alvarez.mariaalejandra@maimonides.edu

1 Departamento de Investigaciones Bioquímicas y Farmacológicas, Laboratorio de Biotecnología Vegetal, CEBBAD, Hidalgo, 775 CABA, Argentina

2 Consejo Nacional de Investigaciones Científicas y Tecnológicas (CONICET), Godoy Cruz, 2290 CABA, Argentina

3 Department of Biochemical Engineering, Nebraska University, Lincoln, NE 68588, USA

4 Farmacobotánica y Farmacognosia, Farmacia y Bioquímica, Facultad de Ciencias de la Salud, Universidad Maimónides-CEBBAD, Hidalgo, 775 CABA, Argentina ultimately resulting in the conversion of prothrombin into the proteolytic enzyme $\alpha$-thrombin (FIIa) as one of its last steps. Then FIIa activates fibrinogen to fibrin, participates in the activation of platelets and other blood coagulation factors (V, VIII, IX, and XIII), and plays a role in the activation of factor $\mathrm{C}$ in the presence of thrombomodulin. Platelets aggregate on the fibrin clot, collagen, and endothelial cells from the injured vessels, initiating sealing that prevents bleeding (DiBella et al. 1995; Heemskerk et al. 2002; Adams and Huntington 2016). If any of the mentioned steps fail, the consequence is a hemorrhage.

The pharmaceutical industry is attracted by the production of proteins involved in the blood coagulation mechanism (Moura et al. 2011; Casademunt et al. 2012; Rech et al. 2014; Santagostino et al. 2014). Particularly, the production of recombinant FIIa, or any of its precursors, is considered of interest for the manufacture of hemostatic sealants. Prethrombin-2, corresponding to amino acids $\mathrm{Thr}_{272}$ to $\mathrm{Glu}_{579}$ of the human prothrombin, is the smallest singlechain precursor of FIIa. The difference between 
prethrombin-2 and FIIa is a cleavage at the position $\operatorname{Arg}_{320^{-}}$ $\mathrm{Ile}_{321}$, followed by the release of a 13 amino acid peptide from the N-terminus. Recombinant prethrombin-2 was already expressed in Escherichia coli (Choi et al. 1989; So et al. 1992; DiBella et al. 1995; Soejima et al. 2001; Osadská et al. 2014). However, that recombinant protein aggregates into inclusion bodies and has to be solubilized and refolded, hindering the recovery of an active, properly folded enzyme. A recombinant FIIa was also expressed in yeast, but the product was not identical to human FIIa (Holly and Foster, 1996). Finally, other precursors of FIIa were expressed in mammalian cell cultures (Le Bonniec et al. 1992; Russo et al. 1997; Oates et al. 2001; Yonemura et al. 2004).

There is an interest in obtaining a reliable source of FIIa utilizing plants as biofactories for recombinant proteins. One of the remarkable traits of plants is that their protein synthesis machinery produces mammal proteins with often only slight differences from the original source. Additionally, plants can perform complex post-translational modifications, such as the formation of disulfide bridges and folding, plant-made proteins do not aggregate as inclusion bodies, and the final product does not carry any risk of contamination with prions, oncogenes, toxins, or human pathogens (Twyman et al. 2012; Fischer et al. 2013; Sabalza et al. 2014; Sack et al. 2015).

When it comes to production, plant systems have the advantage of an easy and economical scale-up. Additionally, in the case of confined production (greenhouses or in vitro cultures), the process can be conducted in environmentally controlled conditions, following good manufacturing practices and good laboratory practices, if required (Sharma and Sharma 2009; Fischer et al. 2012; Twyman et al. 2012; Merlin et al. 2014).

As for the drawbacks, plant-made proteins may have glycosylation modifications (Lerouge et al. 1998; Gomord et al. 2010, Batra and Rathore 2016), and the yields of the recombinant proteins are usually low (Ullrich et al. 2015). Subcellular targeting can enhance protein stability, thus increasing the accumulation of heterologous proteins in plants (Ferraro et al. 2008; Nelson et al. 2012). Endoplasmic reticulum (ER)-retention via the addition of lysine-aspartic acidglutamic acid-leucine (KDEL) to the $\mathrm{C}$-terminus is often used to minimize foreign protein degradation since the ER provides a relatively protected environment, with a high concentration of molecular chaperones and a low presence of proteases (Fischer et al. 2004; Laguia Becher et al. 2010). Meanwhile, the secretion of foreign proteins into the medium of plant cell cultures, where metabolites and contaminant proteins are generally absent, makes for an easier and cheaper protein recovery (Conrad and Fiedler 1998; Doran 2006).

Another factor that influences the yield of recombinant proteins in plants is gene silencing, which can take place at the transcriptional or translational level. Post-transcriptional gene silencing (PTGS) is a defensive response that recognizes foreign RNA, triggering its degradation (Stam et al. 1997; Vaucheret et al. 2001). Some plant viruses have evolved strategies to elude this defense mechanism by expressing proteins that suppress PTGS. Turnip crinkle virus (TCV)-coat protein (CP), not only has a structural role but it also functions as a strong suppressor of PTGS (Qu et al. 2003).

The aim of the present work was to clone and evaluate the expression of two versions of a FIIa precursor (pFIIa), secpFIIa (secretory), and pFIIa-ER (ER-retained) in Nicotiana benthamiana Domin. The influence of PTGS on recombinant protein production in a transient expression system by coexpressing TCV-CP was evaluated. Additionally, pFIIa expression was analyzed in stably transformed callus and cell suspension cultures.

\section{Materials and Methods}

Construction of plant expression vectors Dr. David G. Ross from the University of British Columbia (Vancouver, Canada) kindly provided the human prothrombin coding region (accession no. MN_000506). Two synthetic sequences, comprised of amino acids $\mathrm{Thr}_{285}$ to $\mathrm{Glu}_{579}$ of the human prothrombin (pFIIa), were designed. First, a secretory version (sec-pFIIa) was constructed by adding the signal peptide $2 \mathrm{~S} 2$ from the seed storage protein of Arabidopsis thaliana (L.) Heynh. to the N-terminus of the pFIIa-coding sequence (Krebbers et al. 1988). Secondly, the endoplasmic reticulum-retention version (pFIIa-ER) was obtained by adding the ER-retention motif KDEL to the C-terminus of sec-pFIIa. In both versions (secpFIIa and pFIIa-ER) the Kozak consensus sequence (accatgg) was placed before the $2 \mathrm{~S} 2$ signal and a six histidine tag (6xHis) was added to the C-terminus (Fig. 1A).

The sec-pFIIa and pFIIa-ER transgenes were amplified by a polymerase chain reaction (PCR) using the following primers: forward ( $\mathrm{Fw}) 5^{\prime}$-aaccatggcaaacaagctcttcctc-3' (underlined is an incorporated $\overline{5^{\prime} \mathrm{Nco}} \mathrm{I}$ restriction site) and reverse ( Rv) s e c-pFIIa $5^{\prime}$ - c t c gag tcattaatgatgatgatgatgatgctctccaaactgatc- $3^{\prime}$ for the secretory version, or Rv pFIIa-ER 5' ctcgagtcattatagctcatctttatgatgatgatgatgatgctctccaaactgatc- $3^{\prime}$ for the ER-retention version (underlined is an incorporated 3' XhoI restriction site). The PCR products were cloned into the pGEM®-T Easy vector (Promega ${ }^{\circledR}$, Madison, WI). To confirm the correct synthesis of the genes, both inserts were sequenced using specific primers for the promoters T7 and Sp6. The sec-pFIIa and pFIIa-ER inserts were digested with $N c o$ I and XhoI enzymes and cloned into the entry vector pENTR4 (Invitrogen ${ }^{\mathrm{TM}}$, Carlsbad, CA), previously digested with the same enzymes. The resulting plasmids, pENTR4:sec-pFIIa and pENTR4:pFIIa-ER, were each recombined with the plant binary expression vectors pK7WG2 (pK) and p35SGATFH (p35S) (Karimi et al. 2002; Zanetti et al. 2005) using the 


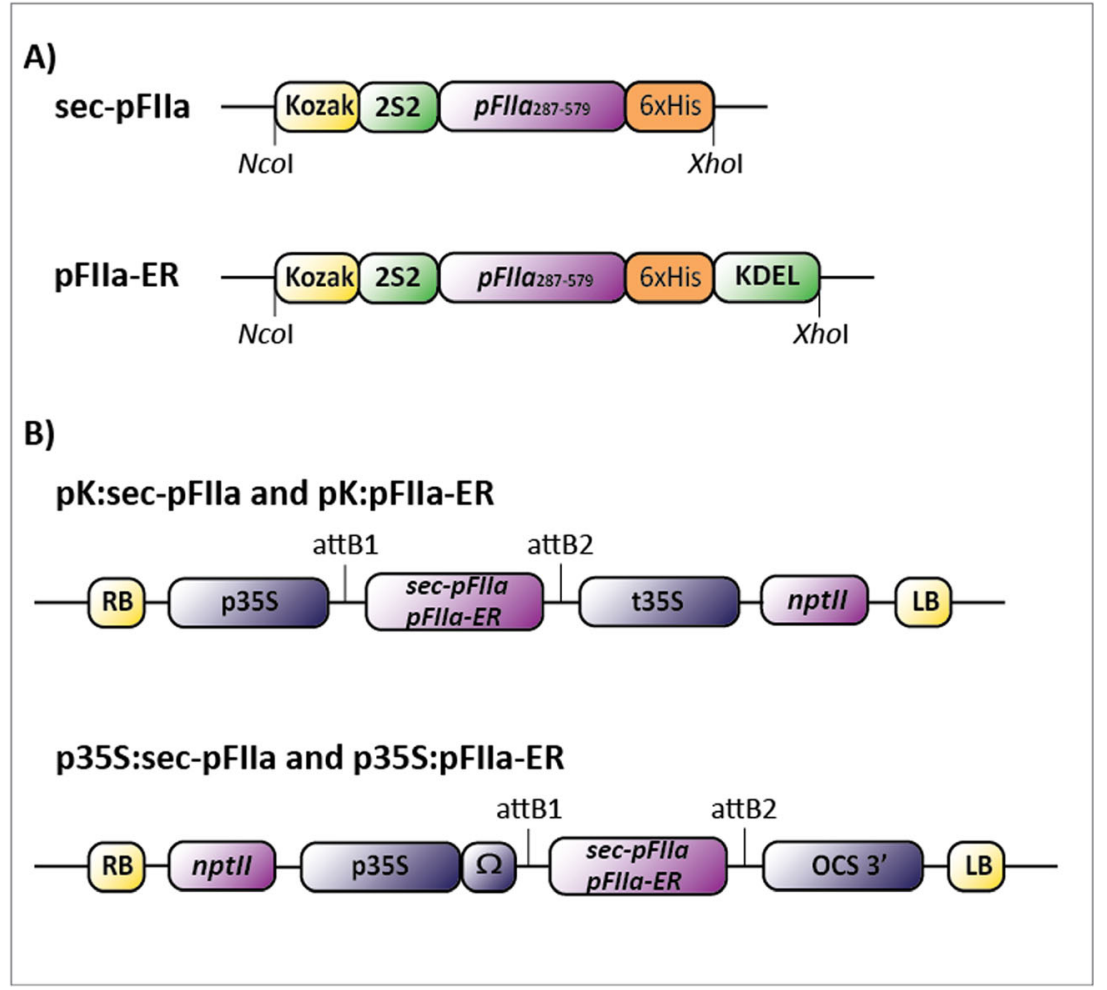

Figure 1. Schematic representation of the constructions used to express the $\alpha$-thrombin precursor pFIIa in Nicotiana benthamiana Domin. (A) Characteristics of the secretory ( $\mathrm{sec}$-) and endoplasmic reticulum $(E R)$ retained pFIIa transgenes. Kozak, Kozak consensus sequence; $2 S 2$, signal peptide from the seed storage protein of Arabidopsis thaliana (L.) Heynh.; 6xHis, six histidine tag; KDEL, ER-retrieval motif; $N c o I$ and

Gateway® LR Clonase ${ }^{\mathrm{TM}}$ II Enzyme Mix (Invitrogen $\left.{ }^{\mathrm{TM}}\right)$. The pK vector contained the Cauliflower Mosaic Virus 35S promoter and terminator (p35S and t35S); meanwhile, the p35S vector contained the same promoter (p35S) with the translational enhancer sequence $\Omega$ from Tobacco Mosaic Virus and the Agrobacterium tumefaciens octopine synthase terminator (OCS 3'; Fig. 1B). In both cases, neomycin phosphotransferase II (nptII) was the selectable marker gene that confers resistance against kanamycin. In the $\mathrm{pK}$ vector, the nptII gene was under the transcriptional regulation of A. tumefaciens nopaline synthase (nos) promoter and terminator (Hellens et al. 2000). In the $\mathrm{p} 35 \mathrm{~S}$ vector, the $n p t I I$ gene was under the control of p35S and t35S (Hajdukiewicz et al. 1994). The resulting four final plant expression vectors were checked by PCR and restriction endonuclease mapping (data not shown).

Agrobacterium tumefaciens infiltration The obtained plant expression vectors $p K$ :sec-pFIIa, pK:pFIIa-ER, p35S:secpFIIa, and p35S:pFIIa-ER were separately introduced into A. tumefaciens strain EHA101 by electroporation. Fresh single colonies of recombinant $A$. tumefaciens clones were inoculated in $10 \mathrm{~mL}$ of Luria-Bertani (LB, Bertani 1951) medium autoclaved for $20 \mathrm{~min}$ at $0.1 \mathrm{MPa}$ of pressure (Arcano, LS-
$X h o I$, restriction enzyme sites. $(\boldsymbol{B})$ Expression vector transfer-DNA (TDNA) regions. $R B$ and $L B$, right and left borders of the T-DNA; $p 35 S$ and t35S, Cauliflower Mosaic Virus 35S promoter and terminator; $\Omega$, Tobacco Mosaic Virus 5' leader sequence; OCS 3', Agrobacterium tumefaciens octopine synthase terminator; nptII, neomycin phosphotransferase II (kanamycin resistance gene); attB1 and attB2, recombination sites.

B75L; Ningbo, China). After the sterilization procedure, the medium was supplemented with $20 \mu \mathrm{g} \mathrm{mL}^{-1}$ rifampicin, $50 \mu \mathrm{g} \mathrm{mL}^{-1}$ kanamycin, and $100 \mu \mathrm{g} \mathrm{mL}^{-1}$ spectinomycin (for $\mathrm{pK}$ vectors) or $50 \mu \mathrm{g} \mathrm{mL}^{-1}$ chloramphenicol (for $\mathrm{p} 35 \mathrm{~S}$ vectors). The antibiotics were filter-sterilized by Millipore MILLEX-GV® $0.22 \mu \mathrm{m}$ Filter unit (Biopore, Buenos Aires, Argentina). Agrobacterium tumefaciens cultures were incubated overnight at $28{ }^{\circ} \mathrm{C}$ and $210 \mathrm{rpm}$ in an environmental shaking incubator (Labnet $®$, 311DS; Edison, NJ). Cultures were centrifuged at $4000 \times \mathrm{g}$ for $15 \mathrm{~min}$ and the pellets were resuspended in an infiltration buffer $(10 \mathrm{mM} 2-(\mathrm{N}-$ morpholino) ethanesulfonic acid (MES) pH 5.5, $10 \mathrm{mM}$ $\mathrm{MgCl}_{2}, 100 \mu \mathrm{M}$ acetosyringone) to a final optical density at $600 \mathrm{~nm}\left(\mathrm{OD}_{600 \mathrm{~nm}}\right)$ of 0.8 (Tatineni et al. 2012).

For co-expression experiments, suspensions containing a pFIIa construction were mixed with an equal volume of A. tumefaciens $\left(\mathrm{OD}_{600 \mathrm{~nm}}=0.8\right)$ carrying the PTGS inhibitor TCV-CP (Qu et al. 2003). As a negative control, a wild-type (WT) A. tumefaciens culture was used. The A. tumefaciens suspensions were kept at $24 \pm 2{ }^{\circ} \mathrm{C}$ for $2 \mathrm{~h}$ after being used for plant transient expression. Nicotiana benthamiana plants were grown from seeds in pots filled with soil and were maintained at 22 to $24{ }^{\circ} \mathrm{C}$ under a 16 -h photoperiod using 
fluorescent daylight lamps (Narva T8 LT 18 W/760-010 daylight, Schwandorf, Germany) with an irradiance intensity of $13.5 \mu \mathrm{mol} \mathrm{m}^{-2} \mathrm{~s}^{-1}$ in a growth room. Six-week-old-plants with six to eight leaves were gently infiltrated with the A. tumefaciens suspensions by inoculation with a $1-\mathrm{mL}$ syringe without a needle into the abaxial side of the lamina (Leuzinger et al. 2013). The A. tumefaciens-infiltrated plants were maintained in a growth room as described before. A minimum of three plants per experimental group was infiltrated (three leaves per plant). For sampling, three leaves per experimental group (one leaf per plant) were harvested at 3 and $5 \mathrm{~d}$ post-infiltration (dpi), frozen in liquid nitrogen, and stored at $-80^{\circ} \mathrm{C}$ until use. Agrobacterium tumefaciens infiltrations, and their corresponding Western blot analyses (see below) were repeated at least three times.

Protein extraction and Western blot analysis Frozen A. tumefaciens-infiltrated leaves were ground in liquid nitrogen to a fine powder using a mortar and pestle and extracted with three volumes of cold Laemmli (1970) buffer (0.5 M tris(hydroxymethyl)aminomethane (Tris)-HCl $\mathrm{pH} 6.5,4 \%$ $(w / v)$ sodium dodecyl sulfate (SDS), 20\% ( $v / v)$ glycerol, 10\% (v/v) 2-mercaptoethanol (Bio-Rad®, Hercules, CA), and $0.1 \%(w / v)$ bromophenol blue). Protein extracts were centrifuged at $17,968 \times \mathrm{g}$ for $20 \mathrm{~min}$ at $4{ }^{\circ} \mathrm{C}$ and total protein concentration (TPC) in the supernatant was measured using the reducing agent and detergent compatible (RC-DC) protein assay (Bio-Rad®) with bovine serum albumin (BSA) as a standard.

Protein samples were boiled for $5 \mathrm{~min}$ and separated by SDS-polyacrylamide gel electrophoresis (SDS-PAGE). Sodium dodecyl sulfate-polyacrylamide gel electrophoresis was performed with a $12 \%$ separating gel and a $5 \%$ stacking gel and run in a Mini-Protean $®$ Tetra cell (Bio-Rad®) at $150 \mathrm{~V}$ for $2 \mathrm{~h}$. The gels were transferred onto Immobilon-P polyvinylidene fluoride (PVDF) membranes (Millipore ${ }^{\mathrm{TM}}$, Billerica, MA) in a Mini Trans-Blot $\AA$ cell (Bio-Rad () at $80 \mathrm{~V}$ for $1 \mathrm{~h}$. The membranes were blocked overnight at $4{ }^{\circ} \mathrm{C}$ with $0.5 \%(w / v)$ casein in Tris-buffered saline, $\mathrm{pH} 7.5$ containing $0.05 \%(v / v)$ Tween ${ }^{\circledR} 20$ (TBST) and then probed for $1 \mathrm{~h}$ at $24 \pm 2{ }^{\circ} \mathrm{C}$ with sheep polyclonal anti-human thrombin antibody (PAHT-S; Haematologic Technologies Inc., Essex Junction, VT) diluted 1:1000 in TBST with $0.5 \%$ $(w / v)$ casein. After three washes in TBST, the membranes were probed for $1 \mathrm{~h}$ at $24 \pm 2{ }^{\circ} \mathrm{C}$ with anti-sheep IgG-peroxidase antibody produced in donkey (A3415; Sigma-Aldrich $\left.{ }^{\circledR}\right)$, diluted 1:15,000 in TBST with $0.05 \%(w / v)$ casein. Immunoreactive complexes were detected by chemiluminescence using Clarity ${ }^{\mathrm{TM}}$ Western enhanced chemiluminescence (ECL) substrate (Bio-Rad®) and the membrane was exposed to Kodak ${ }^{\circledR}$ BioMax ${ }^{\circledR}$ Light Film (Carestream, Rochester, $\mathrm{NY}$ ) for 3 min before it was developed and fixed. The accumulation of pFIIa in N. benthamiana, A. tumefaciens- infiltrated leaves was estimated by comparing plant protein samples with a serial dilution of a known concentration of purified human thrombin (hT; T1063; Sigma-Aldrich ${ }^{\circledR}$ ) electrophoresed on the same polyacrylamide gel. The band intensity of hT detected by Western blot was estimated with the Gel-Pro® analyzer software (Media Cybernetics, Rockville, MD) and used as a standard to build a calibration curve, as previously described by Del L Yácono et al. (2012) and Albarracín et al. (2015). The pFIIa band intensity detected by Western blot was also estimated using the Gel-Pro® analyzer software and compared with the calibration curve obtained by the band intensity of hT. This analysis allowed an estimation of the concentration of pFIIa expressed in the A. tumefaciens-infiltrated leaves.

Relative quantification by real-time PCR Frozen A. tumefaciens-infiltrated leaves $(100 \mathrm{mg})$ were ground to a fine powder in a $1.5-\mathrm{mL}$ microcentrifuge tube using a plastic pestle. Total RNA was extracted using RNeasy ${ }^{\circledR}$ Plant Mini Kit (Qiagen $囚$, Valencia, CA) according to the manufacturer's instructions. The RNA concentration was determined by spectrophotometric analysis. For the complementary DNA (cDNA) synthesis, $2 \mu \mathrm{g}$ of total RNA was reversetranscribed using Invitrogen ${ }^{\mathrm{TM}}$ Superscript ${ }^{\circledR}$ IV First Strand Synthesis System (Thermo Fisher Scientific ${ }^{\circledR}$, Waltham, MA) and random primers. Transcript quantification was performed on the ABI 7500 real-time PCR system (Applied Biosystems $^{\mathrm{TM}}$, Foster City, CA). The pFIIa specific primers (Fw pFIIa 5'-tacaagcetgatgaagggaaac-3' and Rv pFIIa 5'tgagacgatgeccatttgatac-3') were designed with the software PrimerQuest Tool (Integrated DNA Technologies, Skokie, IL). The $N$. benthamiana $60 \mathrm{~S}$ ribosomal protein $\mathrm{L} 23$ was used as the endogenous reference gene (Liu et al. 2012). Polymerase chain reaction amplification efficiency (E) was estimated for each primer set by standard curve measuring tenfold serial dilutions of $100 \mathrm{ng}$ of pool cDNA. The slopes from the regression line plot of cycle threshold (CT) value $v s$. $\log$ of input cDNA were related with PCR amplification efficiency by the formula $(-1 \div$ slope $)$.

Real-time PCR was carried out in a final volume of $25 \mu \mathrm{L}$ using $2.5 \mu \mathrm{L}$ of $1: 15$ diluted cDNA (5 ng), $12.5 \mu \mathrm{L}$ Power SYBR® Green PCR Master Mix 2X (Applied Biosystems ${ }^{\mathrm{TM}}$ ), and $2.5 \mu \mathrm{L}$ of each primer set. The final concentrations of primers used were: $150 \mathrm{nM}$ Fw pFIIa-300 nM Rv pFIIa and $150 \mathrm{nM}$ Fw L23-150 nM Rv L23. The amplification program consisted of a DNA polymerase activation step of $10 \mathrm{~min}$ at $95{ }^{\circ} \mathrm{C}$, followed by 40 cycles of $15 \mathrm{~s}$ denaturation at $95{ }^{\circ} \mathrm{C}$ with a $1 \mathrm{~min}$ annealing and an extension step at $60{ }^{\circ} \mathrm{C}$. Three independent $A$. tumefaciens-infiltrated leaf samples of each construct combination ( $\mathrm{pK}$ :sec-pFIIa, pK:pFIIa-ER, p35S:sec-pFIIa, and p35S:pFIIa-ER \pm TCV-CP) were used with three technical replicates each. 
The relative quantification (RQ) of gene expression was performed using the comparative $\mathrm{CT}(\Delta \Delta \mathrm{CT})$ method in which the amount of pFIIa, normalized to an endogenous reference (L23) and relative to a calibrator (WT), was given by the formula $2^{-\Delta \Delta \mathrm{CT}}$ (Schmittgen and Livak 2008). Relative quantification for the three biological samples and the corresponding technical replicates was calculated using the SDS software V. 1.3 (Applied Biosystems ${ }^{\mathrm{TM}}$ ). The error bars displayed the calculated maximum (RQMax) and minimum (RQMin) expression levels that represented the standard error of the mean expression level (RQ value). Collectively, the upper and lower limits defined the region of expression within which the true expression level value was likely to occur. Prism 5.0 software (GraphPad Software Inc., La Jolla, CA) was used for statistical analysis. Data were compared by oneway analysis of variance (ANOVA) followed by the Bonferroni's multiple comparison tests. A $P$ value $<0.05$ was considered as statistically significant.

Callus cultures $N$. benthamiana plants were A. tumefaciensinfiltrated with the p35S:sec-pFIIa and p35S:pFIIa-ER plasmids as previously described. After $3 \mathrm{~d}$, A. tumefaciens-infiltrated leaves were washed in running tap water, dipped in diluted commercial bleach (55 g Cl L ${ }^{-1}$, Ayudin ${ }^{\circledR}$, Buenos Aires, Argentina) at 3.5\% (v/v) sodium hypochlorite final concentration for $10 \mathrm{~min}$ and rinsed four times in sterilized distilled water to eliminate bacterial cells. Sterilized leaf explants $\left(1 \mathrm{~cm}^{2}\right)$ were placed in Petri dishes containing solid Murashige and Skoog (MS, Murashige and Skoog 1962) medium supplemented with $30 \mathrm{~g} \mathrm{~L}^{-1}$ sucrose, $8 \mathrm{~g} \mathrm{~L}^{-1}$ agar (A296, PhytoTechnology Laboratories ${ }^{\circledR}$, Shawnee Mission, $\mathrm{KS}$ ), and $2 \mathrm{mg} \mathrm{L}^{-1}$ naphthaleneacetic acid (NAA) and $0.2 \mathrm{mg} \mathrm{L}^{-1}$ kinetin (KIN) as plant growth regulators. The $\mathrm{pH}$ was adjusted to 5.7 to 5.8 with $1 \mathrm{M} \mathrm{KOH}$ prior to autoclaving as described before. The medium also contained the filtersterilized antibiotics $50 \mathrm{mg} \mathrm{L}^{-1}$ kanamycin and $500 \mathrm{mg} \mathrm{L}^{-1}$ carbenicillin added after autoclaving. The explants were incubated in a growth room in the same conditions described before. After 2 wk., the explants started to show hyperplasia and after 4 wk. calluses were produced. Calluses were separated and transferred to identical fresh medium without carbenicillin. Each callus was transferred every $3 \mathrm{wk}$. to fresh medium (López et al. 2010, Alvarez et al. 1993). After 6 mo of culture, independent callus lines showing kanamycin resistance were established.

Molecular analysis of transgenic callus lines Genomic DNA was isolated from putative transgenic callus lines. Briefly, $200 \mathrm{mg}$ of callus was ground in a $1.5 \mathrm{-mL}$ microcentrifuge tube using a plastic pestle and extracted with $350 \mu \mathrm{L}$ of DNA extraction buffer $(50 \mathrm{mM}$ Tris-HCl pH 8, $10 \mathrm{~mm}$ ethylenediaminetetraacetic acid (EDTA; Genbiotech SRL, Buenos Aires, Argentina), $100 \mathrm{mM} \mathrm{NaCl}, 1 \%(w / v)$ SDS, and
$10 \mathrm{mM}$ 2-mercaptoethanol). After $10 \mathrm{~min}$ at $65{ }^{\circ} \mathrm{C}, 300 \mu \mathrm{L}$ of $3 \mathrm{M}$ potassium acetate $\mathrm{pH} 5.5$ was added and incubated on ice for $20 \mathrm{~min}$. The samples were centrifuged at $17,968 \times \mathrm{g}$ for 10 min at $4{ }^{\circ} \mathrm{C}$. The supernatant was collected, mixed with one volume of isopropanol, and centrifuged at $17,968 \times \mathrm{g}$ for $15 \mathrm{~min}$. The pellet was washed with $80 \%(\mathrm{v} / \mathrm{v})$ ethanol and resuspended in $40 \mu \mathrm{L}$ of $\mathrm{dH}_{2} \mathrm{O}$. The insertion of the pFIIa transgene into the callus genome was confirmed by PCR screening using the following primers: Fw 5'caccatggcaacaagctcttcctc-3' and Rv 5'atgatgatgatgatgatgctctccaaactgatc- $3^{\prime}$.

Transformation efficiency (\%) was calculated as: (the total number of $\mathrm{PCR}$ positive calluses) $\div$ (total number of kanamycin resistant calluses) $\times 100$.

Finally, for the calluses that exhibited the correct DNA pFIIa transgene fragment of $973 \mathrm{bp}$, the presence of the recombinant protein was analyzed by Western blot as described before. For callus protein extraction, $300 \mathrm{mg}$ of fresh callus tissue was weighed into a $1.5-\mathrm{mL}$ microcentrifuge tube and extracted with $300 \mu \mathrm{L}$ of cold Laemmli buffer using a plastic pestle. Protein extracts were centrifuged at $17,968 \times \mathrm{g}$ for 20 min at $4{ }^{\circ} \mathrm{C}$.

Cell suspension cultures Fresh friable calluses from the lines that expressed higher amounts of pFIIa were transferred to a 225-mL Erlenmeyer flasks containing $50 \mathrm{~mL}$ of MS medium with $2 \mathrm{mg} \mathrm{L}^{-1} \mathrm{NAA}$ and $0.2 \mathrm{mg} \mathrm{L}^{-1} \mathrm{KIN}$ as plant growth regulators and shaken at $100 \mathrm{rpm}$ on an orbital shaker (Mod Bm023, Biomint, Buenos Aires, Argentina) in a growth room as described before. Every $3 \mathrm{wk}$. during a 3-mo period, an inoculum of $5 \%(w / v)$ was transferred to fresh medium and maintained in the same culture conditions (Lopez et al. 2010). Based on the characteristics of cell growth (homogeneous growth with small cell clusters, optimal biomass yield, and lack of oxidation) and the presence of the recombinant protein pFIIa, cell suspension cultures were selected to be scaled up in a stirred-tank bioreactor (Minifors; Infors HT, Bottmingen, Switzerland). An inoculum size of $2 \%(w / v)$ of 10-d-old cell suspensions was transferred to a $2-\mathrm{L}$ vessel containing $1.5 \mathrm{~L}$ of the culture medium with the same composition used before. A marine propeller provided mechanical agitation $(100 \mathrm{rpm})$ and a porous metal sparger supplied a bubble aeration system. The process was performed at $24 \pm 2{ }^{\circ} \mathrm{C}, 0.1$ gas volume flow per unit of liquid volume $\min ^{-1}$ (VVM) set point aeration, and a starting oxygen mass transfer coefficient $(\mathrm{kLa})$ value of $42.7 \mathrm{~h}^{-1}$. The $\mathrm{O}_{2}$ relative partial pressure (OxyFerm 225; Hamilton, Reno, NV) and pH (Mettler Toledo, Columbus, $\mathrm{OH})$ were monitored in line; $\mathrm{O}_{2}$-electrode calibration was made with pure $\mathrm{N}_{2}$. The oxygen uptake rate (OUR) was estimated at $4.57 \mathrm{mmol} \mathrm{O}_{2}(\mathrm{~L} \mathrm{~h})^{-1}$. The whole process was monitored by the Iris Explorer software version 5.2 (Polyhedron Software \& Services LTD., Standlake, United Kingdom). Samples (10 mL per duplicate) were harvested at 0, 2, 4, 6, 
$8,10,13$, and $15 \mathrm{~d}$ and filtered using $0.45 \mu \mathrm{m}$ filter discs with a low protein binding Durapore (PVDF) membrane (Merck Millipore $^{\mathrm{TM}}$, Sao Paulo, Brazil) to separate the biomass from the culture medium. The plant cells were weighed for fresh weight (FW) assessment, which was used as a measure of cell growth. The whole experiment was performed twice.

\section{Protein extraction and enzyme-linked immunosorbent assay}

(ELISA) Samples of cell suspensions were filtered to separate the biomass from the culture medium. Filtered cells $(300 \mathrm{mg}$ ) were powdered in a $1.5-\mathrm{mL}$ microcentrifuge tube in the presence of liquid nitrogen with a plastic pestle and extracted with $300 \mu \mathrm{L}$ of cold Tris-buffered saline (TBS). The homogenized material was placed on ice for $15 \mathrm{~min}$ and centrifuged at $17,968 \times g$ for $20 \mathrm{~min}$ at $4{ }^{\circ} \mathrm{C}$. Total soluble protein (TSP) concentration (in the biomass and the culture medium) was determined according to Bradford (1976) using BSA as the standard protein. Quantification of pFIIa was performed by ELISA sandwich using commercial antibodies. Briefly, 96well Maxisorp® immuno plates (Nunc; Roskilde, Denmark) were coated with $100 \mu \mathrm{L}$ per well of mouse monoclonal antihuman prothrombin antibody (AHP-5013; Haematologic Technologies Inc.) diluted to $2 \mu \mathrm{g} \mathrm{mL}^{-1}$ in carbonate buffer (50 mM pH 9.6) and incubated overnight at $4{ }^{\circ} \mathrm{C}$. Plates were blocked with $250 \mu \mathrm{L}$ per well of TBS containing $1 \%(w / v)$ BSA for $2 \mathrm{~h}$ at $24 \pm 2{ }^{\circ} \mathrm{C}$. For each plate, a standard curve was prepared with $0,0.16,0.31,0.62,1.25,2.5$, and $5 \mu \mathrm{g} \mathrm{mL}$ of purified human prothrombin (HCP-0010; Haematologic Technologies Inc.) diluted in TBS with $0.25 \%(w / v)$ BSA. Plates were incubated with $100 \mu \mathrm{L}$ per well of samples and standards for $2 \mathrm{~h}$ at $24 \pm 2{ }^{\circ} \mathrm{C}$. After five washes with TBST, the plates were probed for $1 \mathrm{~h}$ at $24 \pm 2{ }^{\circ} \mathrm{C}$ with sheep polyclonal anti-human prothrombin antibody conjugated to horseradish peroxidase (P9115-16A; United States Biological, Salem, MA) diluted 1:1000 in TBS with $0.25 \%(w / v)$ BSA. The washes with TBST were repeated and the plates were incubated with a 3,3',5,5'-Tetramethyl-benzidine liquid substrate for ELISA (T0440; Sigma-Aldrich®). The reaction was stopped by the addition of $100 \mu \mathrm{L}$ of $1 \mathrm{~N} \mathrm{HCl}$ and the absorbance was measured at $450 \mathrm{~nm}$ with a microplate reader ( $\mu$ Quant; BioTek Instruments Inc., Winooski, VT). Each sample and standard was assayed in triplicate and the concentrations were interpolated in the linear portion of the standard curve.

All chemical, standards, and solvents were purchased from Sigma-Aldrich® (Saint Louis, MO).

\section{Results and Discussion}

Agrobacterium-mediated transient expression Transformed A. tumefaciens clones were used to infiltrate leaves of $N$. benthamiana. The A. tumefaciens-infiltration experiment was carried out independently three times. The expression of pFIIa was confirmed by Western blot analysis of leaf protein extracts using a polyclonal antibody against human thrombin. As shown in Fig. $2 A$ and $B$, pFIIa was visualized as a faint single band of approximately $35 \mathrm{kDa}$ only at $3 \mathrm{dpi}$, with the exception of pK:pFIIa-ER, where it could not be detected (Fig. 2A). Transient expression usually peaks at $2-3 \mathrm{~d}$ after A. tumefaciens infiltration and then declines quickly as a result of PTGS (Voinnet et al. 2003).

In order to enhance pFIIa expression, co-infiltration with A. tumefaciens containing the silencing suppressor TCV-CP

\section{A)}

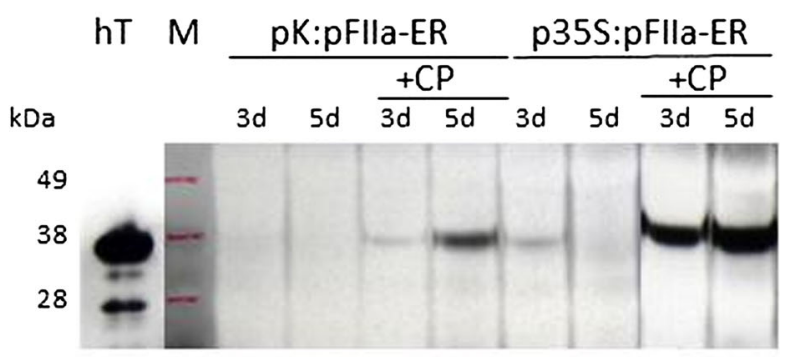

B)

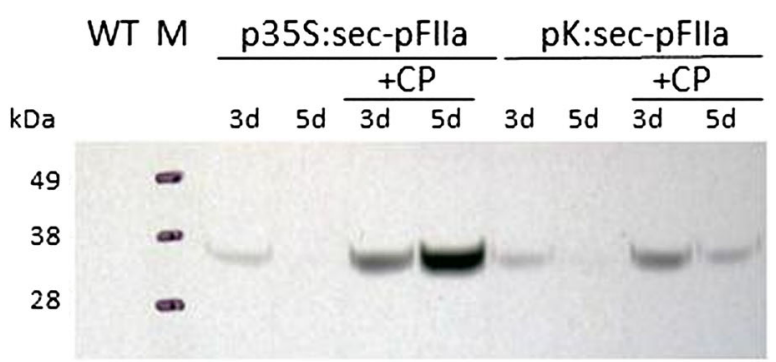

C)

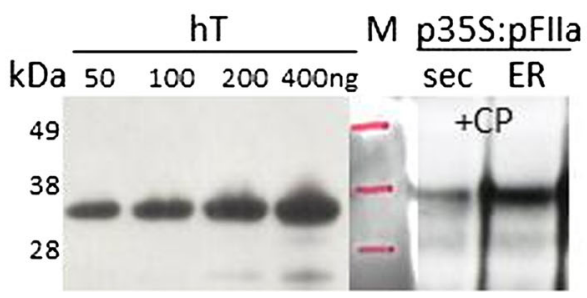

Figure 2. Representative Western blot analysis of the $\alpha$-thrombin precursor $p F I I a$ transient expression in Nicotiana benthamiana Domin leaves. (A) Endoplasmic reticulum (ER)-retained pFIIa version; (B) secreted pFIIa version. (C) Semi-quantification of pFIIa co-expressed with Turnip Crinkle Virus-coat protein $(T C V-C P)$. Total proteins were extracted from Agrobacterium tumefaciens-infiltrated leaves with Laemmli buffer and $15 \mu \mathrm{g}$ was electrophoresed in a $12 \%$ sodium dodecyl sulfatepolyacrylamide gel electrophoresis (SDS-PAGE), transferred to a polyvinylidene fluoride membrane, and probed with a sheep antihuman thrombin polyclonal antibody. $d$, days post- $A$. tumefaciens infiltration; $+C P$, leaves co-A. tumefaciens-infiltrated with TCV-CP; WT, wild-type $N$. benthamiana; $h T$, human thrombin. The pFIIa accumulation was calculated by densitometry analysis on immunoblots using the GelPro analyzer software. Calibration curve was made with 50, 100, 200, and $400 \mathrm{ng}$ human thrombin. The Western blot results presented are representative of three independent experiments. 
was tested. The Western blot analysis showed that pFIIa expression increased and was maintained up to $5 \mathrm{dpi}$ (Fig. $2 \mathrm{~A}$ and $B$, lanes $+C P)$. A higher protein accumulation in A. tumefaciens-infiltrated leaves was achieved when pFIIa expression was driven by $\mathrm{p} 35 \mathrm{~S}$ vector (Fig. $2 A$ and $B$ ). The amount of p35S:pFIIa accumulated in A. tumefaciens-infiltrated leaves was estimated by comparing the intensity of the immunoreactive bands corresponding to pFIIa with a standard curve of purified human thrombin $(50,100,200$, and $400 \mathrm{ng}$; Fig. 2C). The expression level of p35S:pFIIa from the secreted and ER-retained versions was estimated to be 6 and $17 \mu \mathrm{g} \mathrm{g}^{-1}$ $\mathrm{FW}$, which correspond to 0.07 and $0.21 \% \mathrm{TPC}$, respectively, at $5 \mathrm{dpi}$ in the presence of TCV-CP (Fig. 2C). These results indicated that the addition of the KDEL tetra-peptide to the $\mathrm{C}$ terminus of sec-pFIIa and co-expression with TCV-CP had a positive effect on pFIIa accumulation in A. tumefaciens-infiltrated leaves. As it has been previously reported, TCV-CP seems to act as a strong silencing suppressor, preventing PTGS that might have been triggered by recombinant pFIIa production (Qu et al. 2003).

\section{Relative quantification of pFlla expression by real-time PCR} The $\Delta \Delta C T$ method was used to assess and compare pFIIa expression levels in A. tumefaciens-infiltrated leaves. The internal reference gene used was the $60 \mathrm{~S}$ ribosomal protein gene
L23. To ensure the comparability of transcripts, all real-time PCR reactions were performed with equal quantities of cDNA $(5 \mathrm{ng})$. Polymerase chain reaction amplification efficiencies of pFIIa and L23 primer sets were 110 and 105\%, respectively. In all cases, when comparing the same construction with or without the silencing suppressor TCV-CP, a significant increase in pFIIa expression levels in the presence of the TCV$\mathrm{CP}$ was observed. This result showed that the silencing suppressor TCV-CP could efficiently enhance transient expression of pFIIa in $N$. benthamiana, A. tumefaciens-infiltrated leaves by increasing pFIIa transcript levels (Figs. 2 and 3).

Callus culture Stable transgenic calluses were generated with the constructs that yielded the highest accumulated levels in A. tumefaciens-infiltrated $N$. benthamiana leaves (p35S:secpFIIa and p35S:pFIIa-ER). Initial attempts to obtain transformed calluses were made by standard leaf disk transformation using the antibiotics cefotaxime and carbenicillin as bacteriostatic agents. However, the effective concentration of antibiotics needed to suppress A. tumefaciens growth resulted in explant death during the process of callus formation. Therefore, A. tumefaciens-infiltrated $N$. benthamiana leaves were sterilized with $3.5 \%$ sodium hypochlorite solution and used as initial explants for callus cultures. Carbenicillin was added to the medium at $500 \mathrm{mg} \mathrm{L}^{-1}$, a concentration that does

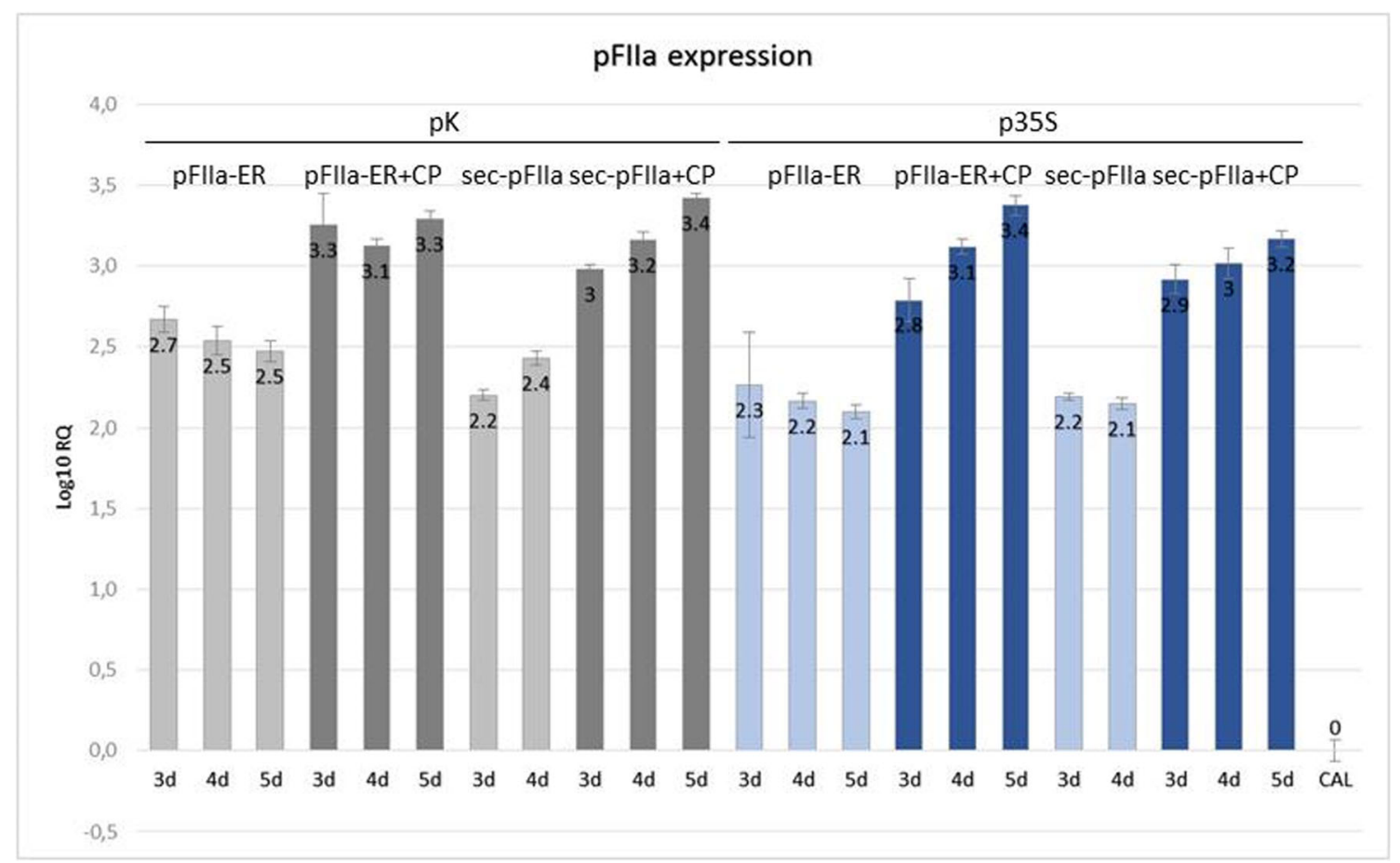

Figure 3. Relative quantification $(R Q)$ of the $\alpha$-thrombin precursor $p F I I a$ expression in Nicotiana benthamiana Domin using quantitative polymerase chain reaction analysis (qPCR). Results shown as fold change ( $\log 10$ $R Q$ ) relative to the wild-type calibrator $(C A L)$. The data error bars represent the standard error of the mean expression level. $p K$, Cauliflower Mosaic Virus 35S promoter and terminator; p35S, Cauliflower Mosaic
Virus 35S promoter followed by translational enhancer sequence $\Omega$ from the Tobacco Mosaic Virus 5' leader sequence and terminated by the Agrobacterium tumefaciens octopine synthase terminator; $p F I I a-E R$, endoplasmic reticulum $(E R)$-retained pFIIa version; $+C P$, leaves coAgrobacterium-infiltrated with Turnip Crinkle Virus-coat protein; secpFIIa, secretory pFIIa version. 
not affect callus formation. This alternative method was effective for eliminating A. tumefaciens. The growth of A. tumefaciens was not detected even after removing the antibiotic. After 6 mo of culture, a total of 23 s-pFIIa and 21 pFIIa-ER putative transgenic callus lines were established. To verify the insertion of the pFIIa transgene into the callus genome, a PCR-based method was carried out for the fast screening of callus clones (Fig. 4A). The transformation efficiency was 52.2 and $66.7 \%$ for sec-pFIIa and pFIIa-ER, respectively. In order to select the callus lines for the establishment of cell suspension cultures, the expression of pFIIa was evaluated by Western blot. Figure $4 B$ shows a weak signal for pFIIa in transgenic callus lines, with different levels of accumulation. These differences in the expression levels of pFIIa might be due to position effects which maybe conducive to gene silencing (Finnegan and McElroy 1994; Gelvin 2003). This result indicated that the yields obtained in calluses were lower than those attained by Agrobacterium-mediated transient expression. Usually, plant cells infected with recombinant $A$. tumefaciens presented multiple copies of transcriptionally active T-DNA molecules that produced large amounts of recombinant protein in a short period of time (Narasimhulu et al. 1996).

Cell suspension cultures Seven transgenic callus lines for each version showing high levels of pFIIa accumulation were selected to establish plant cell suspension cultures. Only two (sec-pFIIa) and four (pFIIa-ER) cell lines were successfully adapted to growth in suspension cultures in Erlenmeyer flasks, having only one of each a good performance in the bioreactor (Fig. 5). The other cell lines, when scaled up exhibited different problems, such as micro-callus formation, cell deposit on the vessel walls, and/or slow growth that hampered the formation of dispersed cell suspensions. The two cell lines that had a good performance in the bioreactor were selected to evaluate their pFIIa production. The line pFIIa-ER showed a cell growth curve with a 4-d lag phase, followed by an exponential phase extended up to the 13th day when the stationary phase started (Fig. 5A). Line sec-pFIIa had a longer lag phase ( $8 \mathrm{~d}$ ), a shorter exponential growth period, and started its stationary phase at the 13th day of culture as well (Fig. 5A). In line secpFIIa, the final biomass was sevenfold higher (approximately $150 \mathrm{~g} \mathrm{FW} \mathrm{L}^{-1}$ ) than the initial biomass, whereas, for line pFIIa-ER, the final biomass was fivefold higher than the initial biomass, corresponding to a growth index (GI) of 6.17 and 3.7 , respectively (Table 1$)$. The specific growth rate $(\mu)$ was higher in the sec-pFIIa line $\left(0.264 \mathrm{~d}^{-1}\right)$ than in the pFIIa-ER line $\left(0.152 \mathrm{~d}^{-1}\right)$, with a doubling time of $2.63 \mathrm{~d}$ and $4.57 \mathrm{~d}$ for sec-pFIIa and pFIIa-ER, respectively (Table 1). The recombinant pFIIa protein from these cell lines was quantified by ELISA. The secreted version of pFIIa remained negligible in the biomass, whereas the ER-retained version of pFIIa increased during the exponential phase, reaching a maximum concentration of $0.25 \mu \mathrm{g} \mathrm{mL}^{-1}(0.017 \% \mathrm{TSP})$ at the 13 th day of the culture (Table 1 and Fig. $5 B$ ). In both cases, the recombinant protein pFIIa was undetectable in the culture medium (data not shown). One possible explanation for the lack of recoverable sec-pFIIa during suspension cultures might be

A)

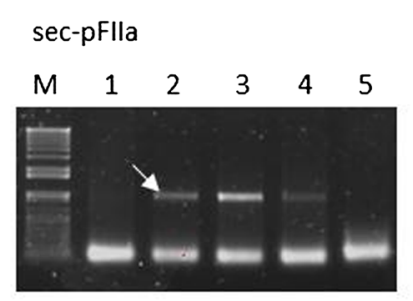

pFlla-ER

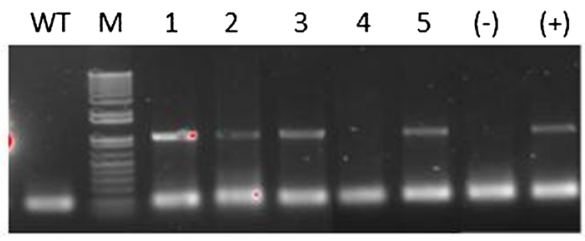

B)

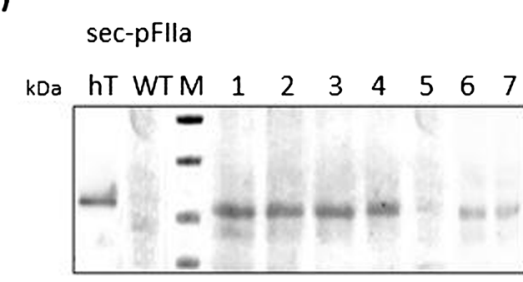

Figure 4. (A) Representative polymerase chain reaction (PCR) amplification for the secretory ( $\mathrm{sec}-$ ) and endoplasmic reticulum $(-E R)$ retrained $\alpha$-thrombin precursor ( $p F I I a)$ sec-pFIIa and pFIIa-ER transgenes from transformed Nicotiana benthamiana Domin callus genome. WT, wildtype callus; $M$, molecular weight standards; lanes 1 to 5 , kanamycin resistant callus lines; (-), negative PCR control; (+), positive control (p35S:sec-pFIIa plasmid). The arrows indicate the expected $973 \mathrm{bp}$ size of the amplification product. $(\boldsymbol{B})$ Representative Western blot analysis of

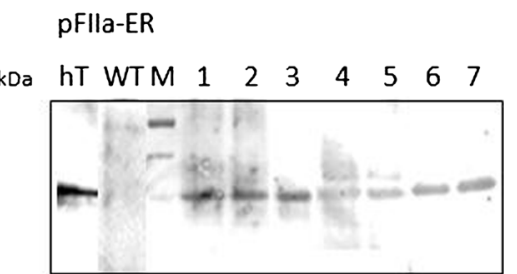

sec-pFIIa and pFIIa-ER expression from transgenic callus lines. Total proteins were extracted from callus with Laemmli buffer. The equivalent to $25 \mathrm{mg}$ of fresh callus per lane were electrophoresed in a $12 \%$ sodium dodecyl sulfate-polyacrylamide gel electrophoresis (SDS-PAGE), transferred to a polyvinylidene fluoride membrane, and probed with a sheep anti-human thrombin polyclonal antibody. $h T$, human thrombin; $W T$, wild-type $N$. benthamiana callus; $M$, molecular weight standards; lanes $1-7$, transgenic callus lines. 
A)

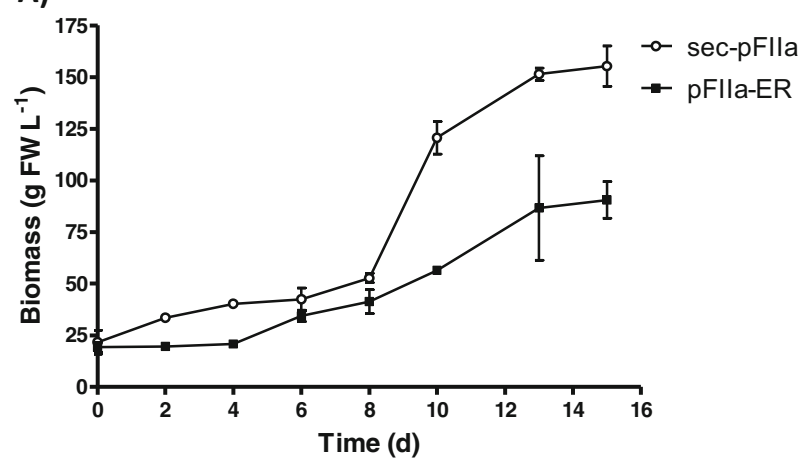

B)

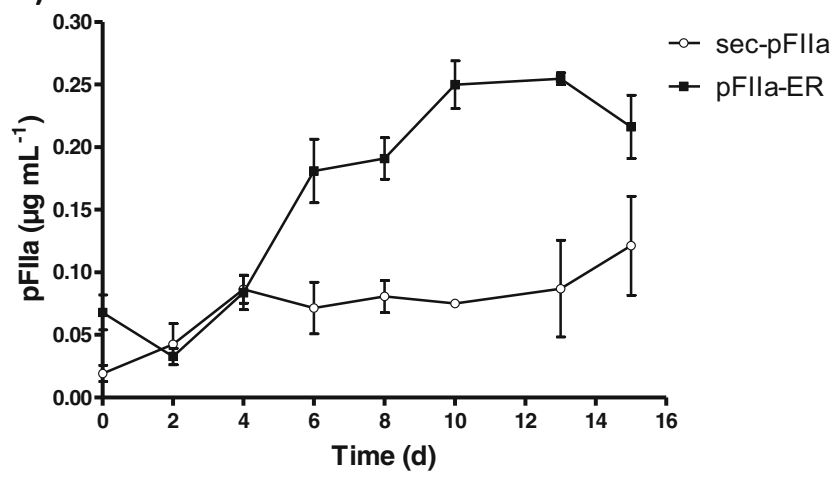

Figure 5. (A) Time course of cell growth of stable Nicotiana benthamiana Domin suspension culture transformed with secretory $(s e c-)$ and endoplasmic reticulum ( $-E R$ ) retrained $\alpha$-thrombin precursor ( $p$ FIIa) sec-pFIIa and pFIIa-ER in bioreactor. Biomass was measured as fresh weight $(F W)$. Each point represents the mean \pm SD value of two replicates. $(\boldsymbol{B})$ Concentration of $p F I I a$ in the biomass. Each point represents the mean \pm SD value of three replicates. In both cases the time of culture was $15 \mathrm{~d}$. The experiment was repeated once with similar results and only one experiment is shown.

that the secreted protein was degraded by host proteases (Doran 2006). Therefore, ways to increase pFIIa accumulation in the culture medium could be achieved by the addition of protease inhibitors and/or by minimizing the effect of extracellular proteases (Huang et al. 2009). From these present results, it was clear that obtaining a suitable line to grow in suspension culture required the screening of a large number of cultures from different callus lines. Additionally, the

Table 1. Growth parameters and $\alpha$-thrombin precursor $p F I I a$ production in stably transformed Nicotiana benthamiana Domin cell suspensions

\begin{tabular}{lll}
\hline & sec-pFIIa & pFIIa-ER \\
\hline$\mu\left(\mathrm{d}^{-1}\right)$ & 0.264 & 0.152 \\
Time of duplication $(\mathrm{d})$ & 2.63 & 4.57 \\
$\mathrm{GI}$ & 6.17 & 3.7 \\
pFIIa $\left(\mu \mathrm{g} \mathrm{mL}^{-1}\right)$ & - & 0.25 \\
\hline
\end{tabular}

sec-, secretory pFIIa version; $-E R$, endoplasmic reticulum retrained pFIIa version; $\mu$, specific growth rate; $G I$, growth index: (final biomass-initial biomass) $\div$ (initial biomass) productivity of the recombinant protein in suspension cultures did not necessarily correlate to the expression level obtained in callus cultures. Callus is a mixture of dedifferentiated cells with different transgene copy numbers and insertion sites (Nocarova and Fischer 2009). If in the present study heterogeneity at the callus stage occurred, then this might account for the variable recombinant protein yields observed in suspension cultures (James and Lee 2006).

The production of pFIIa in stable-transformed suspension cultures was lower than that attained by transient expression in A. tumefaciens-infiltrated leaves. In addition to inherent differences between these two expression systems, PTGS reduction by co-expression with TCV-CP demonstratively enhanced transient pFIIa expression levels. Thus, pFIIa yield in suspension cultures could be enhanced by using PTGS silencing suppressors (Sudarshana et al. 2006; Boivin et al. 2010).

\section{Conclusions}

The present study reports for the first time that a precursor of the human $\alpha$-thrombin was expressed in plants. Transient expression was attained after $3 \mathrm{~d}$ post- $A$. tumefaciens infiltration and the yields were higher when co-infiltration with a PTGS inhibitor was performed $(0.07$ and $0.21 \%(w / w)$ TPC for the secreted and retained version, respectively). As for the stable expression, pFIIa yields were only detected in the version retained in the ER $(0.017 \%(w / w)$ TSP). In no case was the recombinant protein found in the culture medium. Clearly, transient expression yielded higher amounts of pFIIa compared to the stable transformation in the conditions of this present work. Future experiments will be performed in order to optimize the growth parameters, including the culture conditions (light source and intensity, culture medium composition, plant growth regulators, and stabilizing agents) for increasing pFIIa yields in in vitro plant cultures.

Acknowledgments The authors thank Dr. Satyanarayana Tatineni from the University of Nebraska for kindly providing the PZP-TCV-CP plasmid and Ms. Isabel Rillo for her advice and careful revision of the English language. MAA, MLB, and PM are members of Consejo Nacional de Ciencia y Tecnología (CONICET) from Argentina.

Funding information This article received funding from Agencia Nacional de Ciencia y Tecnología (PICT 2010-00552) and Nebraska University (21-1106-4006-2).

\section{References}

Adams TE, Huntington JA (2016) Structural transitions during prothrombin activation: on the importance of fragment 2. Biochimie 122:235-242

Albarracín RM, Becher ML, Farran I, Sander VA, Corigliano MG, Yácono ML, Pariani S, López ES, Veramendi J, Clemente M 
(2015) The fusion of Toxoplasma gondii SAG1 vaccine candidate to Leishmania infantum heat shock protein $83-\mathrm{kDa}$ improves expression levels in tobacco chloroplasts. Biotechnol J 10:748-759

Alvarez MA, Nigra HM, Giulietti AM (1993) Solasodine production by Solanum eleagnifolium Cav. in vitro cultures: influence of plant growth regulators, age and inoculum size. Large-scale production. Nat Prod Lett 3:9-19

Batra J, Rathore AS (2016) Glycosylation of monoclonal antibody products: current status and future prospects. Biotechnol Prog 32:10911102

Bertani G (1951) Studies on lysogenesis I : the mode of phage liberation by lysogenic Escherichia coli. J Bacteriol 62:293-300

Boivin EB, Lepage E, Matton DP, De Crescenzo G, Jolicoeur M (2010) Transient expression of antibodies in suspension plant cell suspension cultures is enhanced when co-transformed with the tomato bushy stunt virus p19 viral suppressor of gene silencing. Biotechnol Prog 26:1534-1543

Bradford MM (1976) A rapid and sensitive method for the quantitation of microgram quantities of protein utilizing the principle of protein-dye binding. Anal Biochem 72:248-254

Casademunt E, Martinelle K, Jernberg M, Winge S, Tiemeyer M, Biesert L, Knaub S, Schröder WO (2012) The first recombinant human coagulation factor VIII of human origin: human cell line and manufacturing characteristics. Eur J Haemat 89:165-176

Choi EH, Kim YJ, Kim JM, Hong HJ, Han MH, Kim J (1989) Cloning and expression of human prethrombin 2 cDNA in Escherichia coli. Korean Biochem J 22:154-160

Conrad U, Fiedler U (1998) Compartment-specific accumulation of recombinant immunoglobulins in plant cells: an essential tool for antibody production and immunomodulation of physiological functions and pathogen activity. Plant Mol Biol 38:101-109

Del L, Yácono M, Farran I, Becher ML, Sander V, Sánchez VR, Martín V, Veramendi J, Clemente M (2012) A chloroplast-derived Toxoplasma gondii GRA4 antigen used as an oral vaccine protects against toxoplasmosis in mice. Plant Biotechnol J 10:1136-1144

DiBella EE, Maurer MC, Scherag HA (1995) Expression and folding of recombinant bovine prethrombin-2 and its activation to thrombin. $\mathrm{J}$ Biol Chem 270:163-169

Doran PM (2006) Foreign protein degradation and instability in plants and plant tissue cultures. Trends Biotechnol 24:426-432

Ferraro G, Becher ML, Angel SO, Zelada A, Mentaberry AN, Clemente M (2008) Efficient expression of a Toxoplasma gondii dense granule Gra4 antigen in tobacco leaves. Exp Parasitol 120:118-122

Finnegan J, McElroy D (1994) Transgene inactivation: plants fight back. Bio/Technology 12:883-889

Fischer R, Schillberg S, Buyel JF, Twyman RM (2013) Commercial aspects of pharmaceutical protein production in plants. Curr Pharm Des 19:5471-5477

Fischer R, Schillberg S, Hellwig S, Twyman RM, Drossard J (2012) GMP issues for recombinant plant-derived pharmaceutical proteins. Biotechnol Adv 30:434-439

Fischer R, Stoger E, Schillberg S, Christou P, Twyman RM (2004) Plantbased production of biopharmaceuticals. Curr Opin Plant Biol 7: $152-158$

Gelvin SB (2003) Agrobacterium-mediated plant transformation: the biology behind the "gene-jockeying" tool. Microbiol Mol Biol Rev 67:16-37

Gomord V, Fitchette AC, Menu-Bouaouiche L, Saint-Jore-Dupas C, Plasson C, Michaud D, Faye L (2010) Plant-specific glycosylation patterns in the context of therapeutic protein production. Plant Biotechnol J 8:564-587

Hajdukiewicz P, Svab Z, Maliga P (1994) The small, versatile pPZP family of Agrobacterium binary vectors for plant transformation. Plant Mol Biol 25:989-994

Heemskerk J, Bevers E, Lindhout T (2002) Platelet activation and blood coagulation. Thromb Haemost 88:186-193
Hellens RP, Edwards EA, Leyland NR, Bean S, Mullineaux PM (2000) Green: a versatile and flexible binary Ti vector for agrobacteriummediated plant transformation. Plant Mol Biol 42:819-832

Holly DC, Foster DC (1996) Methods for producing thrombin. US Patent Number 005527692A

Huang TK, Plesha MA, Falk BW, Dandekar AM, McDonald KA (2009) Bioreactor strategies for improving production yield and functionality of a recombinant human protein in transgenic tobacco cell cultures. Biotechnol Bioeng 102:508-520

James E, Lee JM (2006) Loss and recovery of protein productivity in genetically modified plant cell lines. Plant Cell Rep 25:723-727

Karimi M, Inzé D, Depicker A (2002) GATEWAYTM vectors for Agrobacterium-mediated plant transformation. Trends Plant Sci 7: 193-195

Krebbers E, Herdies L, De Clerq A, Seurinck J, Leemans J, Van Damme J, Segura M, Gheysen G, Van Montagu M, Vandekerckhove J (1988) Determination of the processing sites of an Arabidopsis $2 \mathrm{~S}$ albumin and characterization of the complete gene family. Plant Physiol 87:859-866

Laemmli UK (1970) Cleavage of structural proteins during the assembly of the head of bacteriophage T4. Nature 227:680-685

Laguia-Becher M, Martín V, Kraemer M, Corigliano M, Yacono ML, Goldman A, Clemente M (2010) Effect of codon optimization and subcellular targeting on Toxoplasma gondii antigen SAG1 expression in tobacco leaves to use in subcutaneous and oral immunization in mice. BMC Biotechnol 15:10-52

Le Bonniec BF, Guinto ER, Esmon CT (1992) Interaction of thrombin des-ETW with antithrombin III, the Kunitz inhibitors, thrombomodulin and protein C. structural link between the autolysis loop and the Tyr-pro-pro-Trp insertion of thrombin. J Biol Chem 267:19341-19348

Lerouge P, Cabanes-Macheteau M, Rayon C, Fischette-Lainé A, Gomord V, Faye L (1998) N-glycoprotein biosynthesis in plants: recent developments and future trends. Plant Mol Biol 38:31-48

Leuzinger K, Dent M, Hurtado J, Stahnke J, Lai H, Zhou X, Chen Q (2013) Efficient agroinfiltration of plants for high-level transient expression of recombinant proteins. J Vis Exp 23

Liu D, Shi L, Han C, Yu J, Li D, Zhang Y (2012) Validation of reference genes for gene expression studies in virus-infected Nicotiana benthamiana using quantitative real-time PCR. PLoS One 7:e46451

López J, Lencina F, Petrucceli S, Marconi PM, Alvarez MA (2010) Influence of the KDEL signal, DMSO and mannitol on the production of the recombinant antibody 14D9 by long-term Nicotiana tabacum cell suspension culture. Plant Cell Tissue Organ Cult 103:307-314

Merlin M, Gecchele E, Capaldi S, Pezzotti M, Avesani L (2014) Comparative evaluation of recombinant protein production in different biofactories: The green perspective BioMed Res Int Article ID 136419

Moura RR, Melo LM, de Figueirêdo Freitas VJ (2011) Production of recombinant proteins in milk of transgenic and non-transgenic goats. Braz Arc Biol Technol 54(5) 927-938

Murashige T, Skoog F (1962) A revised medium for rapid growth and bio assays with tobacco tissue cultures. Physiol Plant 15:473-497

Narasimhulu SB, Deng X-B, Sarria R, Gelvin SB (1996) Early transcription of agrobacterium T-DNA genes in tobacco and maize. Plant Cell 8:873-886

Nelson G, Marconi P, Periolo O, La Torre J, Alvarez MA (2012) Immunocompetent truncated E2 glycoprotein of bovine viral diarrhea virus (BVDV) expressed in Nicotiana tabacum plants: a candidate antigen for new generation of veterinary vaccines. Vaccine 30:4499-4504

Nocarova E, Fischer L (2009) Cloning of transgenic tobacco BY-2 cells; an efficient method to analyze and reduce high natural heterogeneity of transgene expression. BMC Plant Biol 9(44):44 
Oates AM, Kupczyk M, Kannelos J (2001) Method for the production of thrombin, US Patent Number 6168938B1

Osadská M1, Boňková H, Krahulec J, Stuchlík S, Turňa J (2014) Optimization of expression of untagged and histidine-tagged human recombinant thrombin precursors in Escherichia coli. Appl Microbiol Biotechnol 98:9259-9270

Qu F, Ren T, Morris TJ (2003) The coat protein of Turnip crinkle virus suppresses post-transcriptional gene silencing at an early initiation step. J Virol 77:511-522

Rech E, Vianna G, Murad A, Cunha N, Lacorte C, Araujo A, Brigido M, Waters M, Fontes A, O'Keefe B, Simpson A, Caballero O (2014) Recombinant proteins in plants. BMC Proc 2014 8(Suppl 4):O1

Russo G, Gast A, Schlaeger EJ, Angiolillo A, Pietropaolo C (1997) Stable expression and purification of a secreted human recombinant prethrombin-2 and its activation to thrombin. Protein Expr Purif 10:214-225

Sabalza M, Christou P, Capell T (2014) Recombinant plant-derived pharmaceutical proteins: current technical and economic bottlenecks. Biotechnol Lett 36:2367-2379

Sack M, Hofbauer A, Fischer R, Stoger E (2015) The increasing value of plant-made proteins. Curr Opin Biotechnol 32:163-170

Santagostino E, Jacobs IC, Voigt C, Feussner A, Limsakun T (2014) Pharmacokinetic results of two phase III clinical studies of coagulation factor IX (recombinant) albumin fusion protein (rIX-FP) in previously treated patients with hemophilia B (PROLONG-9FP). Blood 124:1491

Schmittgen TD, Livak KJ (2008) Analyzing real-time PCR data by the comparative CT method. Nat Protoc 3:1101-1108

Sharma AK, Sharma MK (2009) Plants as bioreactors: recent developments and emerging opportunities. Biotechnol Adv 27:811-832

So IS, Lee S, Kim SW, Hahm KS, Kim J (1992) Purification and activation of recombinant human prethrombin 2 produced in E. coli. Korean Biochem J 25:60-65
Soejima K, Mimura N, Yonemura H, Nakatake H, Imamura T, Nozaki C (2001) An efficient refolding method for the preparation of recombinant human Prethrombin-2 and characterization of the recombinant-derived a-thrombin. Biochem 130:269-277

Stam M, Mol JNM, Kooter JM (1997) The silence of genes in transgenic plants. Ann Bot 79:3-12

Sudarshana MR, Plesha MA, Uratsu SL, Falk BW, Dandekar AM, Huang TK, McDonald KA (2006) A chemically inducible cucumber mosaic virus amplicon system for expression of heterologous proteins in plant tissues. Plant Biotechnol J 4:551-559

Tatineni S, Qu F, Li R, Morris TJ, French R (2012) Triticum mosaic poacevirus enlists $\mathrm{P} 1$ rather than HC-pro to suppress RNA silencing-mediated host defense. Virology 433:104-115

Twyman RM, Schillberg S, Fischer R (2012) The production of vaccines and therapeutic antibodies in plants. In: Wang A, Ma S, (eds.), Molecular farming in plants: recent advances and future prospects. Springer, Dordrecht, Netherlands, pp 145-159

Ullrich KK, Hiss M, Rensing SA (2015) Means to optimize protein expression in transgenic plants. Curr Opin Biotechnol 32:61-67

Vaucheret H, Béclin C, Fagard M (2001) Post-transcriptional gene silencing in plants. J Cell Sci 114:3083-3091

Voinnet O, Rivas S, Mestre P, Baulcombe D (2003) An enhanced transient expression system in plants based on suppression of gene silencing by the 19 protein of tomato bushy stunt virus. Plant J 5: 949-956

Yonemura H, Imamura T, Soejima K, Nakahara Y, Morikawa W, Ushio Y, Kamachi Y, Nakatake H, Sugawara K, Nakagaki T, Nozaki C (2004) Preparation of recombinant $\alpha$-thrombin: high-level expression of recombinant human prethrombin-2 and its activation by recombinant ecarin. J Biochem 135:577-582

Zanetti ME, Chang IF, Gong F, Galbraith DW, Bailey-Serres J (2005) Immunopurification of polyribosomal complexes of Arabidopsis for global analysis of gene expression. Plant Physiol 138:624-635 